\title{
Doppler Lidar System Design via Interdisciplinary Design Concept at NASA Langley Research Center - Part II
}

\author{
Aaron I. Crasner ${ }^{1}$, Salvatore Scola ${ }^{2}$, Jeffrey Y. Beyon ${ }^{3}$, and Larry B. Petway ${ }^{4}$ \\ ${ }^{1}$ Dept. of Electrical Engin. and Comp. Science, Univ. of Michigan, Ann Arbor, MI 48109, USA, acrasner@umich.edu \\ ${ }^{2}$ NASA Langley Research Center, MS 431, Hampton, VA 23681, USA, Salvatore.Scola@nasa.gov \\ ${ }^{3}$ NASA Langley Research Center, MS 488, Hampton, VA 23681, USA, Jeffrey.Y.Beyon@nasa.gov \\ ${ }^{4}$ NASA Langley Research Center, MS 468, Hampton, VA 23681, USA, Larry.B.Petway@nasa.gov
}

\begin{abstract}
Optimized designs of the Navigation Doppler Lidar (NDL) instrument for Autonomous Landing Hazard Avoidance Technology (ALHAT) were accomplished via Interdisciplinary Design Concept (IDEC) at NASA Langley Research Center during the summer of 2013. Three branches in the Engineering Directorate and three students were involved in this joint task through the NASA Langley Aerospace Research Summer Scholars (LARSS) Program. The Laser Remote Sensing Branch (LRSB), Mechanical Systems Branch (MSB), and Structural and Thermal Systems Branch (STSB) were engaged to achieve optimal designs through iterative and interactive collaborative design processes. A preliminary design iteration was able to reduce the power consumption, mass, and footprint by removing redundant components and replacing inefficient components with more efficient ones. A second design iteration reduced volume and mass by replacing bulky components with excessive performance with smaller components custom-designed for the power system. Thermal modeling software was used to run steady state thermal analyses, which were used to both validate the designs and recommend further changes. Analyses were run on each redesign, as well as the original system. Thermal Desktop was used to run trade studies to account for uncertainty and assumptions about fan performance and boundary conditions. The studies suggested that, even if the assumptions were significantly wrong, the redesigned systems would remain within operating temperature limits.
\end{abstract}

Keywords: ALHAT, Doppler Lidar, IDEC, Langley, LARSS, Thermal Analysis, Thermal Design

\section{THERMAL ASPECTS OF DESIGN}

This paper is the continuation of the previous paper Part I, and focuses on the thermal design aspect of the improvement of NDL via IDEC. This section describes only Design Analysis Cycle (DAC) Phase 2 and the thermal analysis process that was used to assess its viability. An identical procedure was used to evaluate all other considered designs.

Part II focuses on the thermal analysis performed for the redesign of the ALHAT NDL support hardware during the summer of 2013. The NDL is mounted during testing to the Morpheus lander, which is described in Part I of this series. The Morpheus lander is operated outside in Houston, TX, where the ambient air temperature can reach above $38^{\circ} \mathrm{C}$ $\left(100.4^{\circ} \mathrm{F}\right)$ during the summer months.

A thermal model of the DAC 2 NDL design, consisting of only the heat sink and all of the electrical components mounted to it, was created using Thermal Desktop v5.5 (see Figure 1). The thermally modeled portion of the system made up just one portion of the overall DAC 2 design, which had other parts that were not modeled because they did not produce significant amounts of heat. All of the components are modeled as solid finite difference bricks with a single node. Only steady state analyses were performed, and therefore heat capacity of each component was not used. For most components, only case temperatures are calculated. However, Component IDs \#5 and \#6 (see Figure 1) required junction temperatures to be calculated. The entire heat sink is modeled as a group of surfaces because it is assumed to be made of Aluminum 6061 which has a high thermal conductivity, meaning gradients through the thickness will be negligible.

The conductance from each component to the heat $\operatorname{sink}\left(G_{\text {flux_cb }}\right)$ comes from the material properties of the interface 
material used. It is assumed that all components will utilize a 3M silicon interface material, with properties defined in [5]. The value of $G_{\text {flux_cb }}$ is calculated using the following equation, where $R$ is the thermal impedance of the interface material obtained from the datasheet [5]:

$$
G_{f l u x_{-} c b}=\frac{1}{R}
$$

The power dissipation of all components are considered to be at nominal usage. The list of components and their respective thermal properties can be found in Table 1.

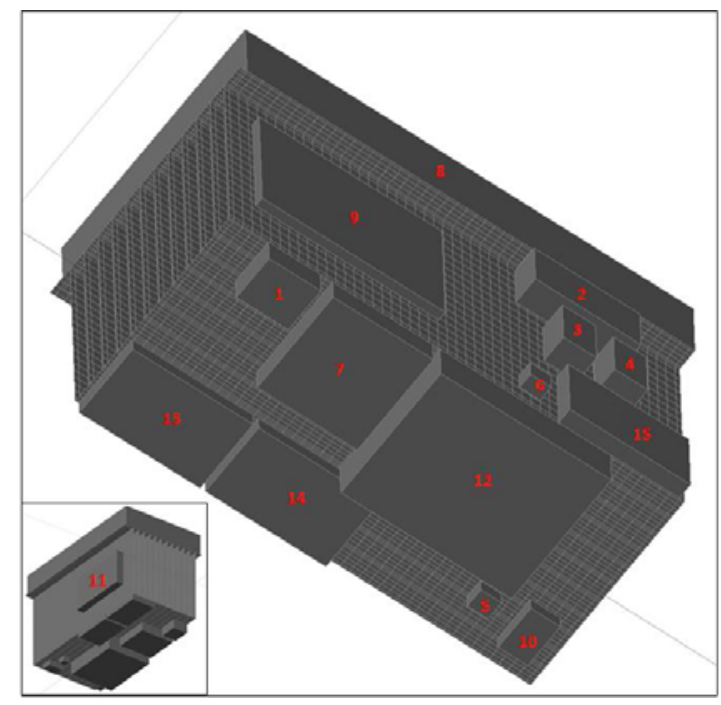

Figure 1 DAC 2 Thermal Model

\begin{tabular}{|c|c|c|c|c|}
\hline $\begin{array}{c}\text { Component } \\
\text { ID\# }\end{array}$ & Mass [kg] & Heat Dissipation [W] & $\begin{array}{c}\mathbf{G}_{\mathbf{f l u x}_{\mathbf{~}} \mathbf{c}} \\
{\left[\mathbf{W} / \mathbf{m}^{2} \mathbf{K}\right]}\end{array}$ & $\boldsymbol{\theta}_{\mathbf{j c}}[\mathbf{K} / \mathbf{W}]$ \\
\hline 1 & 0.021 & 0.79 & 2381 & - \\
\hline 2 & 0.047 & 0.72 & 2381 & - \\
\hline 3 & 0.015 & 0.39 & 2381 & - \\
\hline 4 & 0.015 & 0.75 & 2381 & - \\
\hline 5 & 0.002 & 0.21 & 2381 & 70 \\
\hline 6 & 0.002 & 0.24 & 2381 & 70 \\
\hline 7 & 0.113 & 3.04 & 2381 & - \\
\hline 8 & 1.5 & 8.25 & 2381 & - \\
\hline 9 & 0.10 & 7.00 & 2381 & - \\
\hline 10 & 0.013 & 3.75 & 2381 & - \\
\hline 11 & 0.222 & 2.00 & 2381 & - \\
\hline 12 & 0.200 & 1.60 & 2381 & - \\
\hline 13 & 0.043 & 1.00 & 2381 & - \\
\hline 14 & 0.043 & 1.00 & 2381 & - \\
\hline 15 & 0.043 & 2.40 & 2381 & - \\
\hline
\end{tabular}

Table 1 List of electrical components and thermal properties

Most of the junction to case resistances were not studied, except for two components (ID \#5 and \#6 in Figure 1), as previously indicated. This distinction is made clear by the absence of values for the majority of the components in the junction to case resistance $\left(\theta_{\mathrm{jc}}\right)$ column. The other components' datasheets only provided case temperature limits and did not provide junction to case resistances. 
Forced convection from a fan through the heat sink is assumed to be the only form of heat transfer from the system to the environment. The specified fan produces 120 Cubic Feet per Minute (CFM) at zero pressure drop. To be conservative, the baseline analysis assumed 40 CFM through the DAC 2 heat sink, which becomes $1.84 \mathrm{~m} / \mathrm{s}$ when the open crosssectional area of the heat sink is taken into account. The equation used is as follows, where $v$ is air velocity, $\dot{V}$ is volumetric flow rate, and $A$ is open cross-sectional area in the heat sink:

$$
v=\frac{\dot{V}}{A}
$$

The amount of heat transfer to the environment was modeled by the value of the heat transfer coefficient. The nature of air flow (laminar or turbulent) dictated how to calculate that value, making it necessary to determine which type of flow was present. Assuming a very conservative maximum ambient air temperature of $50^{\circ} \mathrm{C}$, the Reynolds number $(R e)$, which determines the type of flow, was calculated using the following equation (3) for air flow over a flat plate, where $L$ is the length of the plate, $v$ is the air velocity, and $\mu$ and $\rho$ are temperature-dependent properties of air:

$$
\boldsymbol{R e}=\frac{\rho v L}{\mu} ; \quad \text { laminar for } \boldsymbol{R e}<\mathbf{1 0}^{5}-\mathbf{3} \times \mathbf{1 0}^{6}
$$

The Reynolds number was calculated to be within the laminar region, so the equation for laminar flow over a flat plate was used to calculate the heat transfer coefficient $(h)$. The derivation of the equation (3) used is as follows, where $L$ is the length of the plate, $v$ is the air velocity, and $k, \mu, \rho$, and $c_{\mathrm{p}}$ are all temperature-dependent properties of air (values of air properties taken from empirical data [7]):

$$
\begin{aligned}
& \overline{N u}=0.664 \operatorname{Re}^{1 / 2} \operatorname{Pr}^{1 / 3} ; 0.6 \lesssim P r \lesssim 50 \\
& \overline{N u}=\frac{h L}{k} \\
& \operatorname{Pr}=\frac{c_{p} \mu}{k} \\
& h=0.664\left(\frac{k}{L}\right)\left(\frac{\rho v L}{\mu}\right)^{1 / 2}\left(\frac{c_{p} \mu}{k}\right)^{1 / 3}
\end{aligned}
$$

The assumptions indicated above are made with the intention of remaining conservative, meaning that they will lead to a lower heat transfer coefficient than would be expected and will result in higher component temperatures in the analysis.

\section{ANALYSIS RESULTS}

A baseline analysis was performed using the assumptions described in the previous section. The ambient temperature is assumed to be $50^{\circ} \mathrm{C}$ which is conservative for an outside air temperature in Houston, and the heat sink heat transfer coefficient is calculated to be $10.4 \mathrm{~W} /\left(\mathrm{m}^{2} \mathrm{~K}\right)$. This baseline analysis represents an approximation of the main DAC 2 design, with all conservative assumptions included. The results from the baseline case study (see Figure 2) show that most of the components onboard are staying within their temperature limits, with four components exceeding their limits, as displayed by the red numbers in Table 2. An additional analysis with temperature results shown in column 2 of Table 2 suggests that the maximum ambient temperature limit for operation of the NDL is $43^{\circ} \mathrm{C}$. This value is just above the maximum temperature value recorded in Houston of $42.7^{\circ} \mathrm{C}$ [8] and therefore no replacement of any parts is deemed necessary.

As stated in Section 1, the majority of the temperatures listed in Table 2 are case temperatures. The two components (ID \#5 and \#6 in Figure 3) whose junction temperatures were studied are noted. The junction temperatures are calculated from the predicted case temperature in the model by the following equation where $\dot{Q}$ is the heat dissipation of the component, $\theta_{\mathrm{jc}}$ is the junction to case thermal resistance, and $T_{\mathrm{j}}$ and $T_{\mathrm{C}}$ are the junction and case temperatures, respectively: 


$$
T_{j}=\dot{Q} \times \theta_{j c}+T_{C}
$$

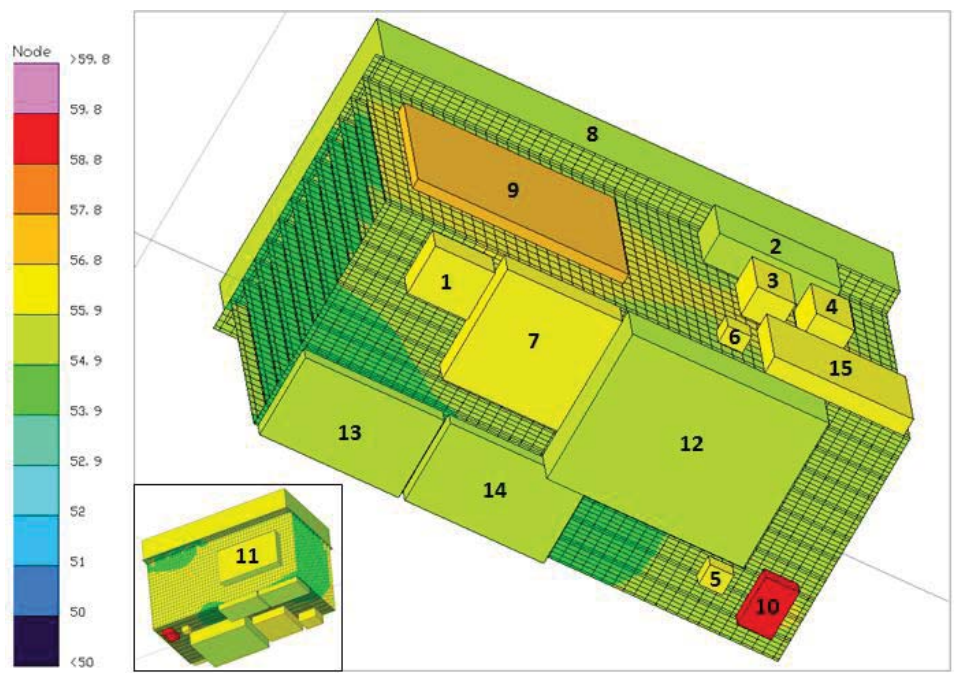

Figure 2 DAC 2 Baseline Thermal Analysis

\begin{tabular}{|c|c|c|c|}
\hline \multirow{2}{*}{$\begin{array}{l}\text { Component } \\
\text { ID\# }\end{array}$} & \multirow{2}{*}{$\begin{array}{c}\text { Max Component } \\
\text { Temperature Limit }\left({ }^{\circ} \mathrm{C}\right)\end{array}$} & \multicolumn{2}{|c|}{ Steady State Temperatures Predictions $\left({ }^{\circ} \mathrm{C}\right)$} \\
\hline & & Ambient $=50^{\circ} \mathrm{C}$ & Ambient $=43^{\circ} \mathrm{C}$ \\
\hline 1 & 85 & 56 & 49 \\
\hline 2 & 85 & 56 & 49 \\
\hline 3 & 85 & 56 & 49 \\
\hline 4 & 85 & 57 & 50 \\
\hline 5 & 160 & 71 & 64 \\
\hline 6 & 160 & 73 & 66 \\
\hline 7 & 100 & 56 & 49 \\
\hline 8 & 50 & 55 & 48 \\
\hline 9 & 85 & 57 & 50 \\
\hline 10 & 70 & 60 & 53 \\
\hline 11 & 70 & 55 & 48 \\
\hline 12 & 85 & 55 & 48 \\
\hline 13 & 50 & 55 & 48 \\
\hline 14 & 50 & 55 & 48 \\
\hline 15 & 50 & 56 & 49 \\
\hline
\end{tabular}

*Junction Temperature

Table 2 DAC 2 electrical component steady state temperatures. Fan performance $=40$ CFM. 


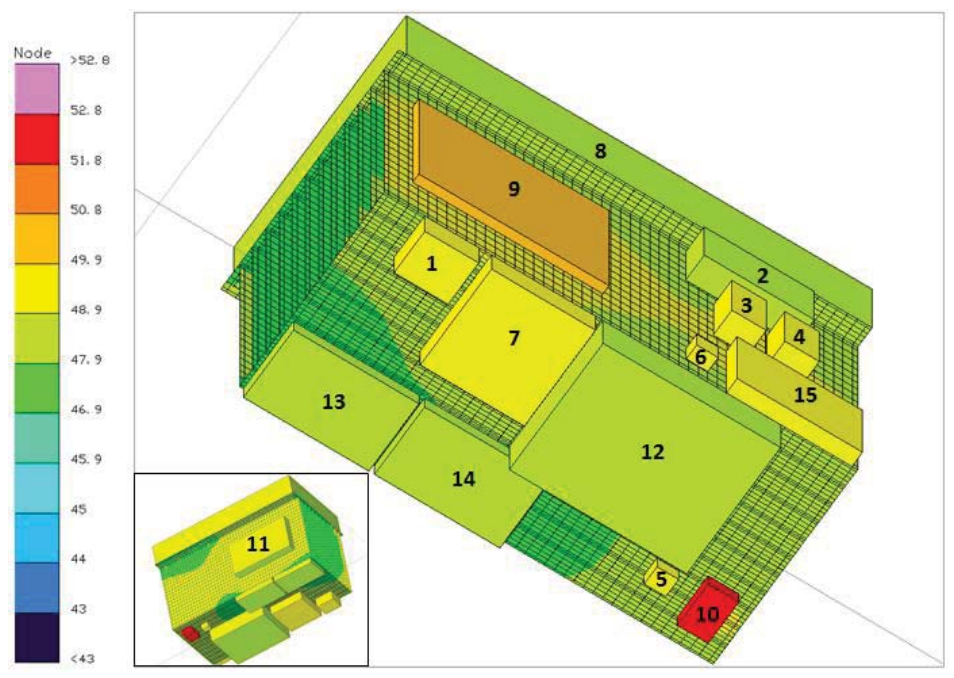

Figure 3 DAC 2 Thermal analysis. $43^{0} \mathrm{C}$ ambient.

In order to provide additional confidence in the design of DAC 2, a trade study was performed to show how much error could be tolerated in the calculated heat transfer coefficient value, which is already very conservative. Each point in Figure 4 represents a different case study, assuming a different fan volumetric flow rate. The ambient temperature is assumed to be $50^{\circ} \mathrm{C}$. The solid red and blue lines represent the hottest and coldest case temperatures of all components onboard, respectively. The yellow points represent the baseline analysis whose results are listed in column 1 of Table 2 above. Only the case temperatures are included in the plot, where the maximum of which was $60^{\circ} \mathrm{C}$ in the baseline analysis. The shaded region in between represents the temperature range in which all other component case temperatures would lie. The dashed red line at $70^{\circ} \mathrm{C}$ indicates the temperature limit for the hottest and most sensitive component, excluding the four previously mentioned that are above the maximum temperature limit of $50{ }^{\circ} \mathrm{C}$ ambient. The results of this trade study show that the DAC 2 components will not begin to experience problematic temperatures unless there is severely reduced fan performance of less than 10 CFM, which is $8.33 \%$ of fan performance at zero pressure drop. DAC 2 is expected to work across a large range of fan performance and will still survive even worse conditions than initially assumed.

DAC 2 Heat Transfer Coefficient Trade Study

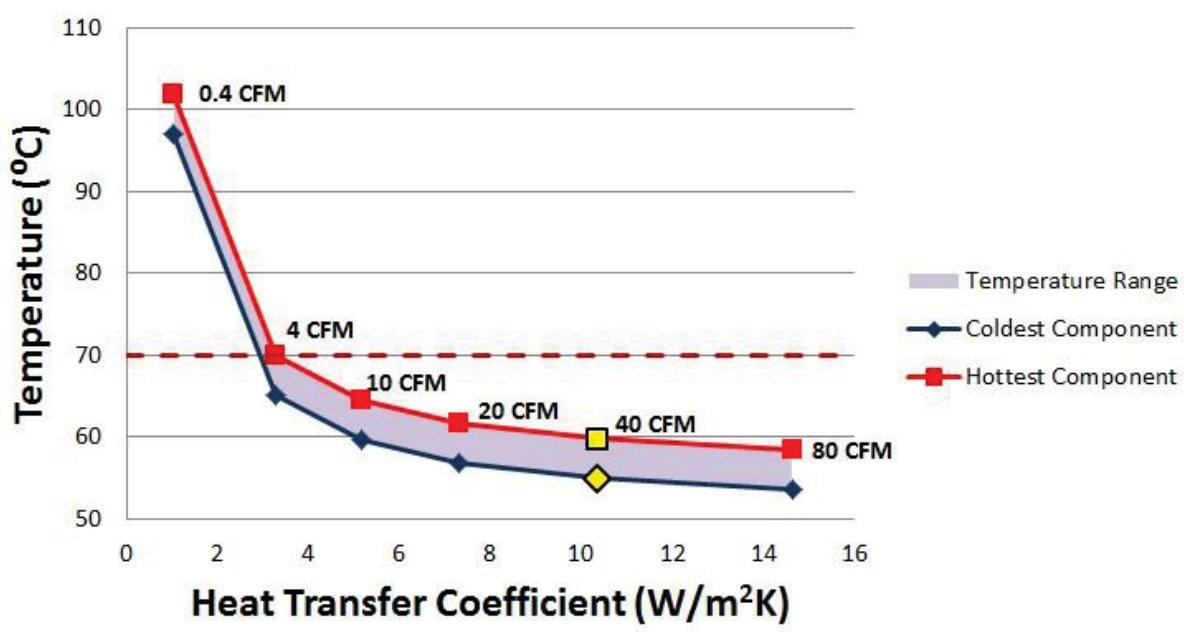

Figure 4 DAC 2 heat transfer coefficient trade study 
At the end of the design project, a prototype of the DAC 2 heat sink was made using a 3D plastic printer in order to determine how much flow loss could be expected through the system. A fan with a rating of 100 CFM at zero pressure drop was used in the test. Air velocity measurements taken at the exit of the far end of the heat sink averaged about 4.5 $\mathrm{m} / \mathrm{s}$. This is greater than the $1.84 \mathrm{~m} / \mathrm{s}$ assumption that the thermal analyses on the system used. This air velocity is 2.4 times higher, which would mean that the fan is pushing approximately $98 \mathrm{CFM}$. This result is promising, as it suggests that there is very little pressure drop through the DAC 2 heat sink. The assumption of a reduction in flow rate from 120 CFM to $40 \mathrm{CFM}$ for the baseline analysis is clearly very conservative. Temperature performance is therefore expected to be better than predicted in Table 2 .

\section{CONCLUSION}

The thermal analysis of the DAC 2 NDL design incorporated several conservative assumptions and attempted to test the model in the worst possible environment. The analysis suggests that DAC 2 will perform to the project standards and is expected to work without thermal failure as long as a maximum environmental operating temperature of $43^{\circ} \mathrm{C}$ is imposed on the system. This should not be an issue for the flight testing location of Houston Texas, where $42.7^{\circ} \mathrm{C}$ is the maximum value on record [8]. Though the design depends on proper function of the fan, the circumstances in which the fan's performance is too low are considered unlikely. Trade studies on the thicknesses of the fins and the walls of the DAC 2 heat sink could also be done to find potential mass savings. If it is desired to further shorten the heat sink (whose length is currently constrained by Component ID\# 8) more efficient fin designs and a smaller version of Component ID\# 8 should be researched. The DAC 2 design was optimized for Earth-based testing, but use of a fan means that DAC 2 will never operate in space. Redesign of the thermal system will be necessary for a future space-flight version of the NDL.

\section{ACKNOWLEDGMENTS}

The authors are grateful for a great deal of guidance and encouragement from the NASA LaRC ALHAT Principal Investigator Dr. Farzin Amzajerdian and the branch heads Ms. Jill Prince, Mr. Steven Gayle, and Dr. Larry Petway in the NASA LaRC Engineering Directorate.

\section{REFERENCES}

[1] Farzin Amzajerdian, Diego Pierrottet, Larry Petway, Glenn Hines, and Bruce Barnes, "Doppler lidar sensor for precision navigation in GPS-deprived environment," Proc. of SPIE ,Vol. 8731, (2013).

[2] Diego Pierrottet, Farzin Amzajerdian, Larry Petway, Bruce Barnes, George Lockard, and Glenn Hines, "Navigation Doppler Lidar Sensor for Precision Altitude and Vector Velocity Measurements Flight Test Results," Proceeding SPIE, Vol. 8044, (2011).

[3] Farzin Amzajerdian, Diego Pierrottet, Larry Petway, Glenn Hines, Vincent Roback and Robert Reisse, "Lidar Sensors for Autonomous Landing and Hazard Avoidance," AIAA Space Conference Proceedings, (2013).

[4] Rutishauser, D., Epp, C. D., and Robertson, E. A., "Free-Flight Terrestrial Rocket Lander Demonstration for NASA's Autonomous Landing and Hazard Avoidance Technology (ALHAT) System," Proc. of AIAA SPACE, 2012.

[5] 3M Company, “3M $3 \mathrm{M}^{\mathrm{TM}}$ Thermally Conductive Silicone Interface Pads.” St. Paula, MN August 2009.

[6] “Compact fans for AC and DC.” ebm-papst. Web. 2011. < http://www.ebmpapst.se/sv/dat/media_manager /news/145/news-files/Compactfans2011.pdf>. 
[7] Çengel, Y. A., Ghajar, A. J. (2011). Heat and Mass Transfer: Fundamentals and applications (4 ${ }^{\text {th }}$ ed.). New York, NY: The McGraw-Hill Companies, Inc.

[8] http://www.srh.noaa.gov/hgx/?n=climate_iah_normals_aug

[9] Czarkowski, Dariusz , and Marian K. Kazimierczuk. Resonant Power Converters. 2nd. Hoboken, New Jersey: John Wiley \& Sons, 2011. Page 487.

[10] Trzynadlowski, Andrzej M. "EMI Effects of Power Converters." In Power Electronics Handbook, edited by Muhammad H. Rashid, 1116. Boston: Academic Press, 2007. Page 1116. 